\title{
ABORDAGEM DA NANOCIÊNCIA E NANOTECNOLOGIA A PARTIR DA ESCALA
}

\author{
Angelisa Benetti Clebsch - IFC/Rio do Sul - PPGECT/UFSC - \\ angelisa.clebsch@ifc.edu.br \\ Marcio Watanabe - IFSC/Gaspar - marcio.watanabe@,ifsc.edu.br
}

Resumo: O desenvolvimento da Nanociência e Nanotecnologia (N\&N) possibilitaram a criação elou avanço de diversos equipamentos modernos utilizados atualmente. A apropriação de conceitos e princípios da N\&N é fundamental à Alfabetização Científica dos estudantes da educação básica. No entanto há uma escassez de materiais didáticos que abordem o tema com linguagem acessivel a estes estudantes. Para contribuir com esta demanda elaborou-se uma hipermídia (vídeo/blog) que possibilita uma aproximação com o tema através da escala, indo "de cima para baixo". Discutese a elaboração do objeto educacional e apresentam-se resultados da análise das interações entre os usuários que o utilizaram. Concluímos que a linguagem direcionada aos usuários, aliada à natureza do objeto desenvolvido, contribuiu na aprendizagem dos assuntos.

Palavras-chave: hipermídia, Nanociência, Nanotecnologia, Alfabetização Cientifica.

\section{APPROACH TO NANOCIENCE AND NANOTECHNOLOGY FROM THE SCALE}

\begin{abstract}
The development of Nanoscience and Nanotechnology (N\&N) has allowed the creation and / or advancement of several modern equipment currently used The appropriation of $N \& N$ concepts and principles is fundamental to students' scientific literacy in elementary schools. However, there is a lack of teaching materials that approach the subject using a language accessible to such students. In order to contribute to this demand, a hypermedia (video/blog) has been developed making it possible a scale approach to the theme "from top to bottom". The elaboration of this educational object is discussed and the results from the analysis of the interactions among its users are presented. It has been concluded that language directed to users, allied to the nature of the developed object, contributed to the subjects' learning.
\end{abstract}

Keywords: hypermedia, Nanoscience, Nanotechnology, Scientific Literacy.

\section{Introdução}

As descobertas sobre a natureza quântica da luz e da matéria no século XX permitiram o desenvolvimento de dispositivos como o transistor, circuito integrado e laser com diversas aplicações tecnológicas em áreas como telecomunicações, medicina e engenharia eletrônica. A crescente necessidade de miniaturização e processamento de um grande número de informações, aliada à invenção de equipamentos para visualização e manipulação da matéria e produção de filmes sólidos em escala atômica, contribuíram com o surgimento da Nanociência \& Nanotecnologia (N\&N).

Historicamente, a fabricação de circuitos eletrônicos utilizando materiais semicondutores e o desafio de interligá-los levou ao desenvolvimento dos circuitos integrados, a partir de técnicas de miniaturização que foram melhoradas. Com a diminuição da escala, houve a necessidade de desenvolver novas formas de integração 
de componentes e miniaturização que permitissem ampliar a capacidade de processamento de microprocessadores e computadores, chegando à escala nanométrica. Pode-se dizer que houve uma continuidade (das tecnologias e da microeletrônica) para uma escala menor, ou seja, "de cima para baixo".

Os termos N\&N tem relação com a escala nano pois envolvem estruturas com pelo menos uma das dimensões menor ou igual a $100 \mathrm{~nm}$ (um nanômetro - nm representa um bilionésimo do metro). A Nanotecnologia pode abranger a manipulação individual de átomos, moléculas, fótons, com construção e operação de dispositivos em escala nanométrica. A manipulação pode acontecer "de cima para baixo" e "de baixo para cima", diferente da microeletrônica que envolve a manipulação "de cima para baixo". Segundo a Sociedade Brasileira de Física (2005), os métodos de nanofabricação "de cima para baixo" representam uma evolução natural de fabricação da microeletrônica. Conforme as limitações da microeletrônica - que tem como base os semicondutores - foram evidenciadas, foi desenvolvida a nanoeletrônica que tem permitido avanços tecnológicos que a microeletrônica não possibilitava. Para Quintili (2012), a técnica de aplicação da Nanotecnologia "de cima para baixo" (Top-dow) envolve o desenho e miniaturização de estruturas para obter sistemas em nanoescala. E as técnicas "de baixo para cima" (Bottom-up) estão centradas "na construção de estruturas e objetos mais grandes a partir de seus componentes atômicos e moleculares" (Quintili, 2012 - tradução nossa).

Atualmente a Nanotecnologia está presente em áreas como informática, medicina, indústria (textil, alimentícia), setor energético, setor agrícola e construção civil. Ela possibilitou o desenvolvimento de nanomaterias e nanopartículas que tornaram os materiais tradicionais mais leves, com maior resistência mecânica e com capacidade de suportar altas temperaturas. Esta temática envolve conhecimentos de várias disciplinas e deve ser trabalhada na Educação Básica, já que os estudantes dispõe hoje de produtos (como raquetes, roupas, celulares, tablets, cartões de memória) que utilizam Nanotecnologia em sua fabricação.

Neste sentido concordamos com Ellwanger, et al. (2012) quando defendem que é necessário a Alfabetização Científica dos estudantes, para que entendam o funcionamento de equipamentos que utilizam em seu dia a dia. O mundo está povoado de tecnologias baseadas no desenvolvimento da N\&N, o que justifica a necessidade de os estudantes da Educação Básica se apropriarem de fundamentos e conceitos de N\&N. $\mathrm{O}$ que pode ser realizado através do estudo integrado ou não de tópicos de Mecânica Quântica, Química, Ciência dos Materiais e Biologia.

$\mathrm{Na}$ busca exploratória por publicações brasileiras da área de ensino de Química e Física, encontramos alguns artigos que podem contribuir com o entendimento do tema ou que trazem sugestões para sua abordagem no Ensino Médio, conforme comentamos a seguir.

Shulz (2005) destaca que a Nanociência não é tão nova e que é possível fazer coisas a partir de átomos, ou seja, de baixo para cima. Apresenta como exemplo de miniaturização o relógio iniciando com os relógios das torres medievais e chegando aos relógios de cristais de quartzo. O mesmo autor (Shulz, 2007) argumenta que para os estudantes a Nanociência está associada a uma atividade realizada em laboratório. Neste aspecto, os estudantes podem considerar que a Nanotecnologia é algo distante de seu dia a dia.

A aproximação do mundo da Nanociência: a questão da medida, o auto-arranjo, a modificação nas propriedades dos corpos na escala nano são questões que devem ser 
discutidas em sala da aula. Uma possibilidade de abordagem da Nanotecnologia nesta direção foi apresentada por Ramos, et al., (2012). Os autores utilizaram modelos de nanoestruturas de carbono com materiais alternativos, a partir dos quais foram exploradas propriedades eletrônicas dos nanotubos de carbono e sua relação com o arranjo dos átomos.

De acordo com Pereira et al. (2010), há uma escassez de fontes e materiais didáticos relacionados à Nanotecnologia no Brasil. Na análise de fontes do exterior, foi observada pelos autores dificuldade em abordar os conceitos com uma linguagem apropriada para alunos dos ensinos fundamental e médio. Como contribuições à essa escassez há a produção de objetos pedagógicos e unidades didáticas que contemplam demonstrações computacionais, animações, vídeos e hipertextos propostos por Ellwagner, et al. (2012).

De acordo com Jesus e Higa (2014), os vídeos são a proposta de ensino mais utilizada para a abordagem da temática no ensino médio brasileiro. No entanto, o que mais aparece é a utilização de documentários já prontos. Apenas um dos trabalhos, da revisão bibliográfica realizada por estes autores, relata a elaboração de vídeo didático, com foco na produção de nanopartículas.

Tendo em vista as colocações anteriores optamos por construir uma hipermídia ${ }^{1}$, na forma de hipertexto que traz um blog e um vídeo, com uma linguagem simples e acessível à estudantes da Educação Básica. Além da linguagem e da contribuição para preencher a lacuna acerca da escassez de materiais didáticos sobre N\&N, abordamos o tema sobre outro aspecto, através da aproximação com a escala indo "de cima para baixo". Uma abordagem diferente de demais materiais com foco, por exemplo, na utilização da imagem de estruturas químicas relacionadas a objetos do cotidiano dos estudantes (Pereira et. al, 2010), uso de modelos (Ramos et al., 2012), propriedades ópticas em nanoescala (Ellwagner, et. al, 2012) e produção de nanopartículas (Rebello et al., 2012).

Nossos objetivos com este artigo são: 1) apresentar o objeto educacional construído, para sua utilização no Ensino de Ciências; 2) trazer resultados de seu uso com licenciandos e estudantes da Educação Básica. Faremos a apresentação e discussão do objeto educacional produzido, seguido de alguns resultados de sua utilização.

\section{Procedimentos metodológicos}

Inicialmente selecionamos assuntos que fariam parte do material didático e discutimos alternativas para sua construção. Optamos pelo blog, que apresenta uma estrutura em ordem cronológica inversa. Com acesso à várias páginas, sem compromisso com a sequência didática.

Além disso, resolvemos construir um vídeo, para explorar recursos audiovisuais. Dentre os mais variados editores de vídeo, escolhemos o Windows Live Movie Maker, justamente por oferecer a possibilidade de inicialização na edição de vídeos. O software é simples e fácil de utilizar, pois permite que indivíduos sem muita habilidade em edição de vídeos possam adicionar efeitos de transição de imagens, inclusão de áudio e textos personalizados. Outras vantagens do software são: não necessita de um computador potente para ser executado e é gratuito para usuários que

10 termo hipermídia é utilizado, tendo em vista o sentido etimológico da palavra dada pelo dicionário: "Conjunto de informações armazenadas e veiculadas por meio de um computador, que permite que o usuário tenha acesso a diversos documentos (textos, imagens estáticas, vídeos, sons etc.) por remissão associativa com de hipertextos" (http://michaelis.uol.com.br).

V. $15 \mathrm{~N}^{\mathrm{o}} 1$, julho, 2017 
contam com o sistema operacional Windows, visto que o Movie Maker faz parte do pacote de aplicativos deste sistema. A utilização do editor de vídeos Movie Maker para fins educacionais pode ser notada nos trabalhos de Oliveira et al. (2012), Anele \& Carneiro (2012) e Hartmann et al. (2012).

Elaboramos um vídeo com cerca de quatro minutos, que explora a experimentação sobre a escala, em especial, a escala nano, bem como as controvérsias do tema Nanotecnologia. A figura 1 apresenta a abertura do vídeo com o tema central Nanociência. Tal título estilizado é fruto do destaque que queremos dar para a escala nano $\left(10^{-9} \mathrm{~m}\right)$ de modo que chame a atenção dos estudantes para esta escala.

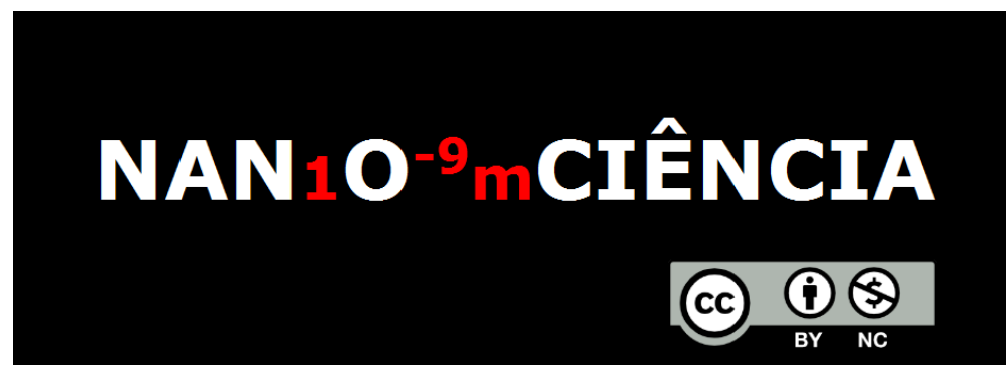

Figura 1 - Imagem da página de abertura do vídeo

Na perspectiva de publicar o vídeo, como uma ferramenta didático-pedagógica, para que possa ser útil aos interessados em tratar de assuntos de Nanociência e Nanotecnologia, postamos o vídeo no youtube. Além disso, no sentido de ampliar a discussão sobre as questões tratadas no vídeo, disponibilizamos o mesmo no endereço http://nanocienciaetecnologia.blogspot.com.br (figura 2), construído no blogspot, ferramenta que por sua vez é acessível aos usuários do gmail do Google.

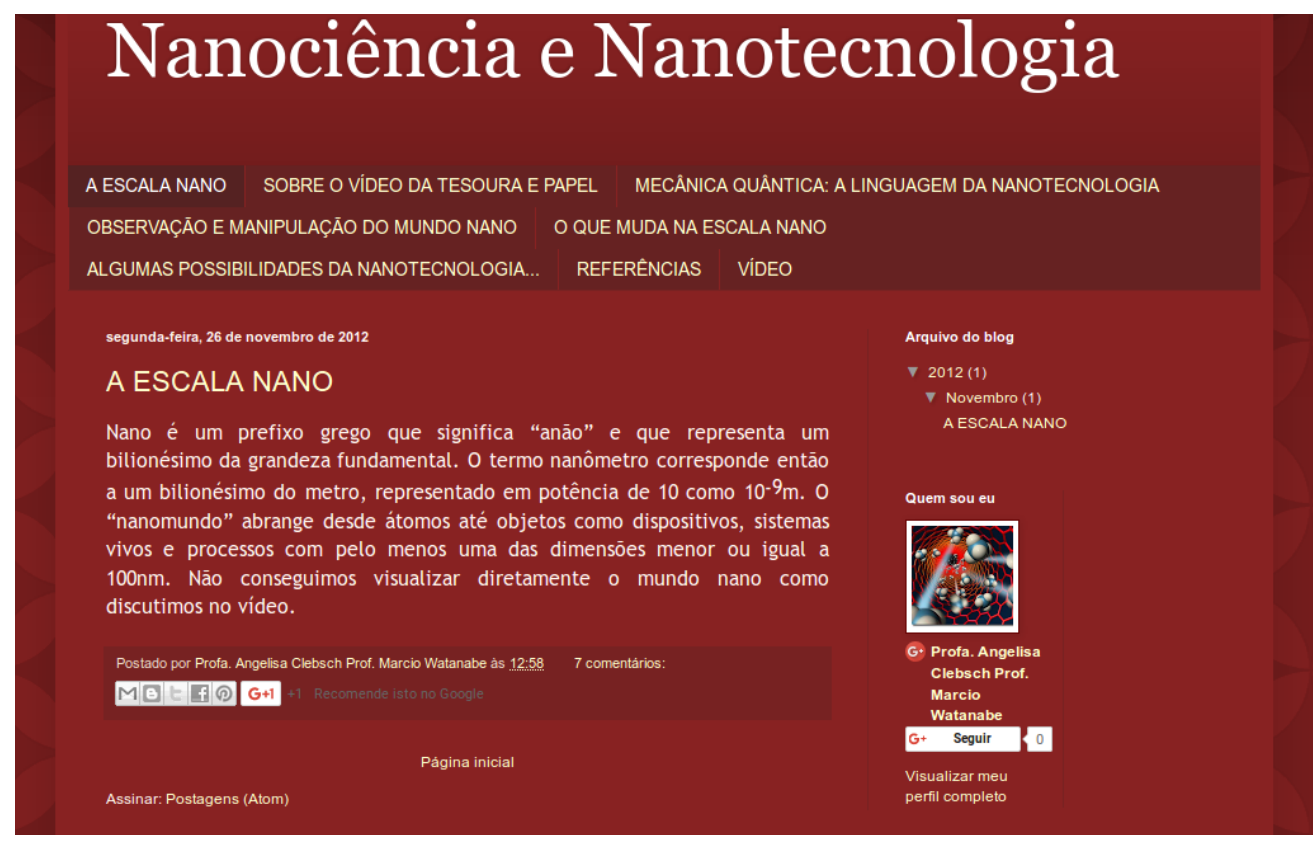

Figura 2 - Blog elaborado para ampliar a discussão do vídeo

Optamos pelo blog pela facilidade de construção e pela possibilidade de atualização através de novas postagens. Deixamos espaço aberto para comentários tendo em vista o objetivo de sua utilização com os estudantes. Consideramos que o objeto 
educacional (vídeo/blog) além de trazer elementos sobre a temática em questão, instiga à reflexão e ao debate da N\&N. Neste sentido a participação dos estudantes através de comentários complementa a hipermídia construída, que possibilita a interação dos usuários através do envio de comentários.

Faremos a apresentação de resultados da utilização do material através da análise de postagens feitas pelos estudantes, classificadas da seguinte forma: a) Nanociência e Nanotecnologia: postagens centradas no tema; b) Hipermídia: comentários que mencionam o vídeo ou o blog.

\section{Apresentação e discussão do vídeo}

Ao longo da produção do vídeo, tivemos o cuidado de inicialmente destacar que a Nanociência abrange o estudo das propriedades dos materiais em escala nanométrica. Para uma aproximação com a escala, propomos um experimento que utiliza tesoura e papel A4. Posteriormente, introduzimos a Nanotecnologia como resultado da capacidade de intervenção científica e tecnológica nas propriedades estruturais da matéria em dimensões nanométricas, com o objetivo de desenvolver materiais com propriedades melhoradas ou totalmente novas. Com base nessa definição, incluímos no vídeo a afirmação "Nós seres humanos podemos medir e manipular a matéria na escala nano!". Para apontar como medimos e manipulamos a matéria, apresentamos no vídeo figuras ilustrativas dos equipamentos de microscopia de varredura por sonda e de força atômica. Dessa maneira, destacamos a diferenciação entre os conceitos de Nanociência e Nanotecnologia.

Outro aspecto destacado no vídeo é o caráter multidisciplinar da Nanotecnologia, visto que ela abrange conhecimentos de diversas áreas, tais como, Física Quântica, Química Quântica, Ciências Biológicas, Engenharia Elétrica, Engenharia Mecânica, Ciências dos Materiais, Ciências da Computação, entre outras áreas.

$\mathrm{O}$ vídeo foi estruturado com uma sequência de imagens e frases sobre o tema $\mathrm{N}$ $\& \mathrm{~N}$, de acordo com as seguintes etapas:

(1) Problematização do tema Nanociência a partir da questão: "Será que podemos medir diretamente todas as coisas?". O objetivo da questão é despertar o interesse sobre a mensuração de diferentes objetos, incluindo os materiais de tamanho nano;

(2) Inclusão de imagens de objetos macroscópicos com suas respectivas medidas em quilômetros, metros, centímetros, milímetros e micrômetros, de acordo com o exemplo da figura 3, abaixo. A inserção de imagens visa apontar o comportamento decrescente da escala até a nanométrica.

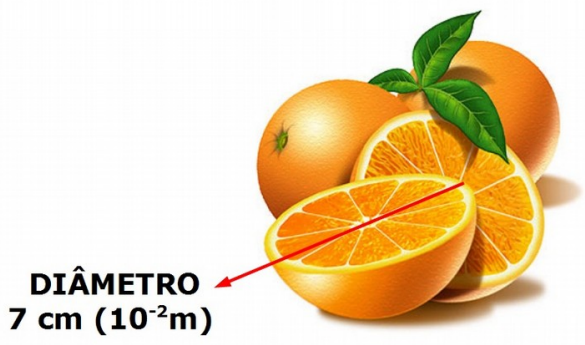

Figura 3 - Imagem representativa do diâmetro da laranja 
(3) Destaque para a escala: "A escala nano é muito pequena" e "Representa um bilionésimo do metro" acompanhada da questão "Será que conseguimos chegar lá?". As frases foram incluídas no sentido de estimular a execução do experimento que é proposto logo em seguida.

(4) Apresentação de um experimento envolvendo o uso de papel A4 e tesoura. A experimentação proposta por Ostermann (2001) reproduzida por nós no vídeo, ilustra a incapacidade de atingir manualmente, sem o uso de equipamentos modernos, a escala nano. O experimento consiste no corte sucessivo do papel A4 ao meio com o auxílio de uma tesoura.

(5) Diante da negativa em atingir a escala nano constatada na experimentação do papel A4, o vídeo aponta equipamentos e diversos exemplos de materiais nanotecnológicos construídos pelo ser humano. Para dar ênfase ao aspecto da construção da Ciência, é apresentada a frase: "Descubra o que o ser humano é capaz de fazer...". Além disso, a afirmação "Nós seres humanos podemos medir e manipular a matéria na escala nano”, com a intenção de refletir sobre a capacidade dos seres humanos envolvida no desenvolvimento da Nanotecnologia.

(6) Além dos exemplos nanotecnológicos, o vídeo lança frases na perspectiva de convite para discussão do tema, tais como, "Reflita...”, “... questione criticamente” e "Participe desse debate". De modo incisivo foram incluídas problematizações que o tema trouxe para a sociedade, em função do campo desconhecido que se depara esta nova Ciência. Sendo elas: "O que a nanotecnologia tem a ver com você?", "As nanopartículas podem ser perigosas para o ser humano e para o meio ambiente?", "Uma vez penetrada nas células dos seres vivos, para onde vão?", "Quais os efeitos sobre o DNA, sistema imunológico e trato cardiorrespiratório?" e "Quais os riscos e as consequências?" O intuito aqui é convencer da importância da participação na discussão do tema.

(7) Por fim, o vídeo explora a frase "Aventure-se no mundo nano!" com a finalidade de mostrar o lado desconhecido do tema, uma vez que não é de domínio pleno dos cientistas e da sociedade os malefícios da Nanotecnologia.

\section{Apresentação e discussão do blog}

Para ampliar os temas abordados no vídeo, o blog apresenta postagens em linguagem adaptada para estudantes da Educação Básica, permitindo a inserção de comentários e o estabelecimento de diálogos sobre o tema. Sem compromisso de sequência didática, os tópicos apresentados no blog são os seguintes:

(1) "Sobre a escala nano" que explica a ordem de grandeza e abrangência da escala nano.

(2) "Sobre o experimento de tesoura e papel" que discute o experimento e explica como o mesmo pode ser reproduzido. Além disso, através da frase " $E$ impossivel fazer tantos cortes manualmente e visualizar os constituintes da folha A4 diretamente" alerta para a dimensão da escala. São apresentados valores aproximados da dimensão de átomos e núcleos em nanômetros.

(3) "Mecânica Quântica: a linguagem da nanotecnologia" explica essencialmente o que diferencia a Física Quântica da Física Clássica. Discute a importância da Física Quântica para o desenvolvimento da Nanotecnologia e Nanociência e apresenta eventos históricos que marcaram o seu surgimento. 
(4) “Observação e manipulação do mundo nano" que apresenta o princípio de funcionamento do microscópio de varredura por sonda e do microscópio de força atômica utilizados para visualização e manipulação da matéria na escala nano, bem como para a produção de novos materiais. Também é mencionada a produção de filmes sólidos com controle de espessura em escala atômica.

(5) "O que muda na escala nano" que discute modificações significativas que ocorrem nas propriedades dos objetos quando a escala nano é atingida. Ainda a questão da auto-organização utilizada na definição de novos produtos e materiais.

(6) "Algumas possibilidades da nanotecnologia" apresenta setores de aplicações da nanotecnologia, como indústria química, cosméticos, agricultura, indústria automobilística e eletrônica: "Na eletrônica os avanços em nanotecnologia tem permitido a miniaturização de processadores e sensores." Algumas propriedades dos nanotubos de carbono são citadas.

(7) "Vídeo": convida o usuário a acessar o vídeo. Apresenta a foto inicial do vídeo que funciona como link para rodar o mesmo.

Cada um dos tópicos acima está disposto em uma página separada. Seu acesso é feito através do título que fica na parte superior do blog e funciona como um link para entrar no conteúdo de interesse.

\section{Interações possibilitadas pela mídia}

A hipermídia foi apresentada por um dos autores deste artigo, para licenciandos em Física, no ano de 2014, em disciplina de Metodologia para o Ensino de Física, no Instituto Federal Catarinense (IFC). Com o objetivo de discutir o tema, como também as possibilidades da utilização da hipermídia na educação básica. Já no ano de 2016, a hipermídia foi utilizada pelo outro autor do artigo, no Instituto Federal de Santa Catarina (IFSC) com estudantes do curso técnico em Química. Neste caso, o objeto educacional foi usado para a abordagem da N\&N, na unidade curricular de FísicoQuímica II.

Nas duas situações, o usuários (licenciandos e estudantes) foram convidados a interagir com os autores e entre si, através da postagem de comentários, cujo espaço foi aberto em cada um dos tópicos do blog.

Ao analisar o número de comentários nos tópicos do blog, observamos que o maior impacto foi com relação ao vídeo, que teve o maior número de comentários, como pode ser visto na figura 4 , abaixo.

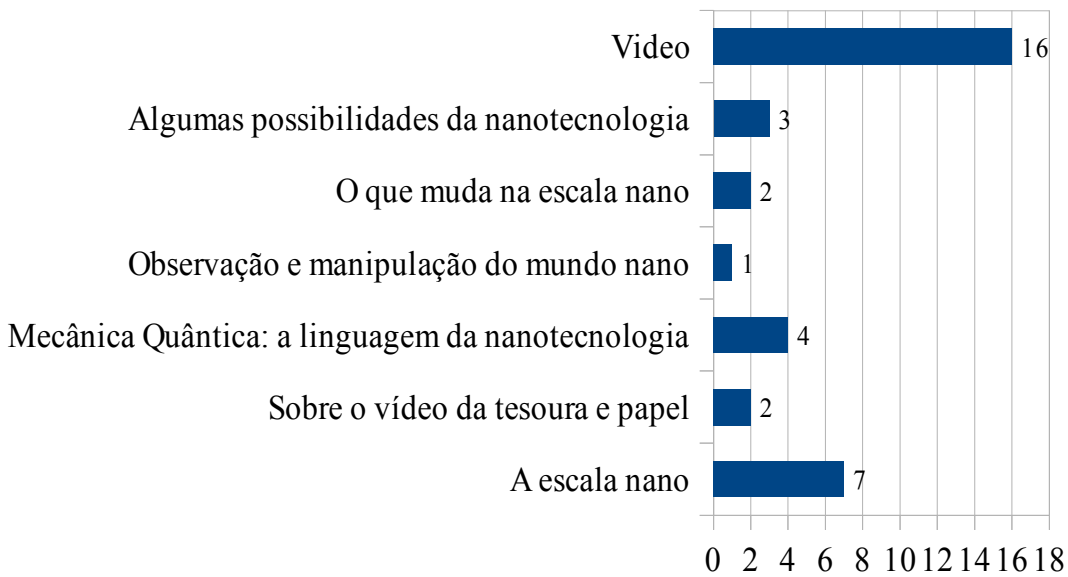

Figura 4 - Número de comentários em cada um dos tópicos do blog 
Pela figura acima, pode ser observado que a questão da escala também obteve um bom número de comentários (7), o que se destaca em relação aos outros tópicos com um número de comentários entre 1 e 4.

Através da análise do conteúdo das postagens no blog, apresentada na figura 5, pode-se perceber o impacto da hipermídia e a receptividade do conteúdo nano pelos estudantes da licenciatura e do Ensino Médio.

\begin{tabular}{|c|c|c|}
\hline & Apontamentos dos estudantes do EM & Apontamentos dos licenciandos \\
\hline $\begin{array}{l}\text { Nanociência e } \\
\text { Nanotecnologia }\end{array}$ & $\begin{array}{l}\text { - Percepção que a N\&N é } \\
\text { multidisciplinar. } \\
\text { - Percepção das várias possibilidades } \\
\text { propiciadas pelo avanço da Ciência. } \\
\text { - Comentários sobre a capacidade de } \\
\text { manipular e ver a matéria na escala } \\
\text { nano com o uso dos microscópios. }\end{array}$ & $\begin{array}{l}\text { - Possibilidade de aprofundamento em } \\
\text { discussões sobre constituição da } \\
\text { matéria. } \\
\text { - Sugestão de utilização de analogias } \\
\text { para a aproximação com a escala. } \\
\text { - Percepção da presença da } \\
\text { Nanotecnologia em componentes } \\
\text { eletrônicos e na medicina. }\end{array}$ \\
\hline Hipermídia & $\begin{array}{l}\text { - Possibilitou o entendimento da } \\
\text { N\&N. } \\
\text { - Possibilitou o entendimento da } \\
\text { escala nano. } \\
\text { - Material de fácil compreensão. } \\
\text { - O experimento de tesoura e papel } \\
\text { auxiliou no entendimento da escala. } \\
\text { - Auxiliou na compreensão da } \\
\text { Mecânica Quântica. } \\
\text { - Compreensão das aplicações da } \\
\text { Nanotecnologia. } \\
\text { - Incentivo à pesquisar sobre } \\
\text { Nanotecnologia. }\end{array}$ & $\begin{array}{l}\text { - Despertou curiosidade com relação } \\
\text { ao tema. } \\
\text { - Permitiu visualizar possibilidades da } \\
\text { N\&N. } \\
\text { - Mostra a impossibilidade de chegar à } \\
\text { escala nano manualmente. } \\
\end{array}$ \\
\hline
\end{tabular}

Figura 5 - Comentários sobre o tema e sobre a hipermídia

Fonte: elaborado pelos autores. Dados do blog em 5/5/2017.

\section{Considerações finais}

O desenvolvimento da N\&N são resultado da produção humana, são de grande abrangência e tem impactos globais. Em busca da miniaturização evoluímos da eletrônica para a microeletrônica e para a nanoeletrônica. Avanços possibilitados pela contribuição de várias Ciências, a exemplo da Química Quântica e da Física Quântica.

Conhecer minimamente os princípios, conceitos, processos, envolvidos na N\&N é necessário à Alfabetização Científica dos estudantes da Educação Básica. Afinal o exercício da cidadania e o debate sobre as tecnologias, processos, produtos produzidos com a evolução da Nanotecnologia requer conhecimento.

Como dizem Ellwanger, et al. (2012) a Nanociência e a Nanotecnologia precisam ser incluídas na educação dos estudantes, para que desenvolvam um senso crítico com relação às inovações tecnológicas desenvolvidas atualmente. Este senso crítico pode envolver o questionamento/debate sobre as consequências de utilização de nanopartículas em tratamentos médicos e de estética corporal. Em países da Europa, como por exemplo, a França, o tema é amplamente debatido, conforme podemos evidenciar na wikipédia francesa (http://fr.wikipedia.org/wiki/Nanotechnologie). 
Através da análise do conteúdo dos comentários, evidenciamos que a hipermídia que desenvolvemos possibilitou a discussão do tema com estudantes e com licenciados, despertando o interesse pelo seu aprofundamento. Concluímos também que a linguagem utilizada, direcionada aos usuários, aliada ao objeto desenvolvido (vídeo/blog) contribuiu na aprendizagem dos assuntos.

O blog possibilitou fazer comentários sobre o vídeo, neste aspecto as duas mídias utilizadas no objeto educacional se complementaram. Percebemos que a página sobre o vídeo recebeu o maior número de comentários, evidenciando positivamente a sua utilização e eficiência no entendimento do tema. O material poderá ser utilizado por outros professores, sendo uma contribuição à escassez de materiais didáticos sobre N\&N como apontado em artigos que acessamos (Pereira, et al., 2010; Jesus e Higa, 2014). Sugerimos sua utilização como organizador prévio para motivar os estudantes ao estudo do tema.

Podemos concluir que pelo fato de o objeto educacional ser de acesso aberto, democratiza a incursão no assunto. Permite que usuários interessados se aproximem e/ou enriqueçam seus conhecimentos sobre N\&N. Dois estudantes, através de comentários postados, afirmam que irão indicar o material para familiares e amigos, que tem curiosidade no assunto. $\mathrm{O}$ vídeo elaborado e postado no youtube teve um número de acessos considerável (mais de mil e duzentos até maio de 2017), com um número crescente de visualizações entre 2012-2017. Neste ponto, além de ser uma material didático, o vídeo pode constituir-se também em material de divulgação científica.

\section{Referências bibliográficas}

ANELE, C. I. F.; CARNEIRO, M. L. Construindo Vídeos: Autoria e Interação Favorecidas no Laboratório de Informática de Escola Pública. Revista Renote: Novas Tecnologias na Educação, Porto Alegre, n. 3, p. 1-10, dez. 2012.

ELLWANGER, A. L.; ROSSATO, J.; GRANADA, M.; BERTOLUZZI, V. I.; FAGAN, S. B. O ensino de nanociências por meio de objetos de aprendizagem. Revista Renote: Novas Tecnologias na Educação, Porto Alegre, v. 10, n. 1, p. 1-10, jul. 2012.

HARTMANN, Â. M.; FLÔRES, M. L. P.; MARTINS, M. A. R.; WELANG, R. B.; ALVARENGA, A. M.; SCHMIDT, A. M.; HALMENSCHLAGER, K.; SILVEIRA, D. S.; PACHECO, G. Transformando experiência em conhecimento durante oficinas para uso de programas computacionais no contexto escolar. Revista Renote: Novas Tecnologias na Educação, Porto Alegre, n. 3, p. 1-10, dez. 2012.

JESUS, I. P.; HIGA, I. Nanotecnologia e Ensino Médio: uma revisão bibliográfica sobre propostas didáticas. In: Simpósio Nacional de Ensino de Ciência e Tecnologia SINECT, 4, 2014, Ponta Grossa - PR. Anais. Ponta Grossa: Universidade Tecnológica Federal do Paraná/Sinetec, $2014 . \quad$ Disponível em:

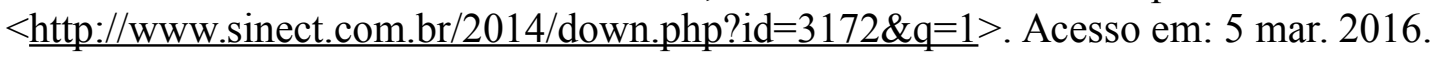

OLIVEIRA, M. L.; ANTUNES, A. M.; TELlES, M. P. C.; MORAIS, S. M. T. S. Genética na TV: o Vídeo Educativo como Recurso Facilitador do Processo de EnsinoAprendizagem. Revista Eletrônica Experiências em Ensino de Ciências, Mato Grosso, n. 1, p. 27-42, mai. 2012.

OSTERMANN, F. Partículas elementares e interações fundamentais. Porto Alegre: Instituto de Física - UFRGS, 2001. 74 p. (Textos de apoio ao professor de Física, n. 12) 
PEREIRA, F. D; HONÓRIO, K. M; SANNOMIYA, M. Nanotecnologia: Desenvolvimento de Materiais Didáticos para uma Abordagem no Ensino Fundamental. Revista Química Nova na Escola, São Paulo, v. 32, n. 2, p. 73-77, mai. 2010.

QUINTILI, M. Nanociencia y Nanotecnología... un mundo pequeño. Cuaderno 42, Centro de Estudios en Diseño y Comunicación, Buenos Aires, Argentina, pp 125-155, set. 2012.

RAMOS, D. A.; TAKAHASHI, E. K.; KAGIMURA, R. Conciliação entre pesquisa científico-tecnológica e a área de ensino: lições sobre propriedades físicas de novos materiais de carbono para o Ensino Médio. In: Encontro de Pesquisa em Ensino de Física - EPEF, 14, 2012, Maresias, São Sebastião, SP. Anais. São Paulo: Sociedade Brasileira de Física/XIV EPEF, $2012 . \quad$ Disponível em: $<$ http://www.sbf1.sbfisica.org.br/eventos/epef/xiv/sys/resumos/T0079-1.pdf $>$. Acesso: nov. 2012.

REBEllo, G., A. F.; ARGYROS, M. M.; LEITE, W., L. L.; SANTOS, M. M.; BARROS, J. C.; SANTOS, P., M. L. e SILVA, J., F. M. Nanotecnologia, um tema para o ensino médio utilizando a abordagem CTSA. Revista Química Nova na Escola, São Paulo v. 34, n. 1, p. 3-9, fev. 2012.

SHULZ, Peter, A. B. Nanociência de baixo custo em casa e na escola. Física na Escola, v. 8, n. 1, mai. 2007.

SHULZ, Peter, A. B. O que é nanociência e para que serve a nanotecnologia. Física na Escola, v. 6, n. 1, mai. 2005.

SOCIEDADE BRASILEIRA DE FÍSICA. Física para o Brasil: pensando o futuro. Editores: Alaor Chaves e Ronald Cintra Shellard. São Paulo: Sociedade Brasileira de Física, 2005, 248 p. 